\title{
KEUZE EN OPLEIDING VAN NAAR WEST-INDIE UIT TE ZENDEN RECHTERLIJKE EN BESTUURSAMBTENAREN
}

DOOR

\author{
MR. F. G. SCHALKWIJK
}

oud-Rechter in Curaçao en Suriname

Niet alleen Oost-Indië beleeft een merkwaardigen opbloei, ook in ons West-Indië ontwaakt nieuw leven. De Doornroosjes Curaçao en Aruba zijn wakker gekust door den Petroleumkoning, en, indien de plannen van den „Ondernemersraad" in vervulling gaan, staat ook voor Suriname, met een alsdan overwegende Javanenbevolking, nog een goede toekomst open. Zal, zoo rijst de vraag, het kleine Westindische ambtenarencorps opgewassen zijn tegen een zooveel ruimere bestuurstaak?

Het verschil in keuze, voorbereiding en leven tusschen den hoogeren ambtenaar voor Oost- en dien voor West-Indië is treffend, ja bijna stuitend. Aan de geestelijke uitrusting van den eersten wordt alle zorg besteed. In eene Academiestad wordt hem door de beste krachten kennis bijgebracht van taal, recht, zeden, economie en geschiedenis van de volken, waaronder hij arbeiden zal. Indonesië is groot: door verplaatsing leert hij heel een Archipel kennen, geleidelijk slagen hij en zijn gezin erin zich aan te passen aan een nieuwe, tropische omgeving. Is hij ziek, er is gelegenheid in het land zelf om op zijn verhaal te komen. Zijn loopbaan is, onder normale omstandigheden, een regelmatige, hij weet, dat hij zich over zijn toekomst niet ongerust behoeft te maken en dat het einde komt met een behoorlijk pensioen.

Hoe anders vergaat het den Westindischen ambtenaar. Van eenige opleiding of voorbereiding voor de hoogere 
ambten is geen sprake. Ontstaat in West-Indië een vacature, de afdeeling West-Indië van het Departement van Koloniën plaatst een advertentie en wacht af, wat zich bij geval opdoet.

Het aantal gegadigden is als regel gering, vogels van diverse pluimage, sommigen aangetrokken door positieverbetering, het meerendeel avontuurlijken van aard, die het goede oogenblik verzuimd, of de gelegenheid gemist hebben vroeger een werkkring in Oost-Indië te verwerven en wien nu althans de weg naar West-Indië nog openstaat, enkelen gedreven door zuivere belangstelling voor de West en door overwegingen, welke Multatuli blij deden zijn, dat Lebak arm was.

Blijkt het den sollicitanten meestal al spoedig, dat de uitzendingsvoorwaarden, van naderbij beschouwd, niet meevallen, het Departement doet zijnerzijds de steeds terugkomende ervaring op, dat onder de gegadigden niet alles timmerhout is. Een dikwijls langdurig en onverkwikkelijk loven en bieden tusschen Departement en sollicitant begint. Salaris en uitrustingskosten worden, als het moet, met dikwijls zooveel afgunst verwekkende extratoelagen verhoogd, door toezeggingen voor herplaatsing in Hollandschen dienst na afloop van het verband wordt, zoo noodig, het ambt nog smakelijker gemaakt. De uitverkoren sollicitant, de onzekerheid beu, of wel tenslotte te ver door onderhandelingen gebonden dan dat hij nog terug kan, bezwijkt ten lange leste, laat zich benoemen, vertrekt.

Het verblijf in West-Indië valt het gezin niet mee. Kan de man, meestal al wat ouder, het klimaat bij hard werken al verdragen, de vrouw doet het zelden, het onderwijs van de kinderen sluit als regel niet aan. Opvattingen omtrent rassenverschillen zijn den nieuwkomers geheel vreemd. Op de Benedenwindsche Curaçaosche eilanden brengt het Papiamento - het Negerspaansch - hem onbekend, doch in den omvang algemeen gebruikt, hem van de wijs. Op de Bovenwindsche Eilanden werkt het Engelsch in administratie en rechtspraak in den beginne verwarrend. Al wordt in Suriname Hollandsch gebezigd tot 
in den kleinen burgerstand toe, wie het Negerengelsch niet kent, blijft vreemd tegenover zijn omgeving. De Britsch-Indiër en Javaan, met eigen taal en zeden, geven eveneens sterk het gevoel vreemd te staan tegenover een bevolking, waarover men niettemin gezag moet uitoefenen.

Ook overigens beantwoordt het land niet aan de meestal aan Oostindische toestanden ontleende voorstellingen eener tropische maatschappij.

In plaats van eene omgeving, waarin hij als Hollander krachtens nationaliteit, kleur en intellect gemakkelijk een eerste plaats inneemt, vindt hij in den kring, waarin hij zal hebben te leven, een kleine, doch uitgelezen inheemsche blanke bevolking, meest van ouder tot ouder daar gevestigde Joodsche en Hollandsche families, een plaatselijke aristocratie, die hem de baas is in locale kennis altijd, in wereldwijsheid en ruimte van middelen, dikwijls, en die het hem, den Hollander, den „macamba” in Curaçao, den ,bakra” in Suriname, d. i. den vreemdeling, den vijand, niet onduidelijk doet gevoelen, dat het haar niet ongevallig zou zijn, indien hij de beste en hoogst bezoldigde ambten, die hij thans komt waarnemen, en die zij, naar zij meent, even goed behartigen kan, dan ook aan haar overliet.

Een door onwennigheid geprikkelde stemming onder het Hollandsche ambtenarencorps is een vruchtbaar veld voor moeilijkheden en conflicten, voor ontijdige uitbarstingen van verborgen lichaams- en zielsgebreken. Komt het einde door ontslag of afkeuring al niet voor het verstrijken van den tijd der uitzending-meestal vijf jarendan is het toch bij het ambtenaarsgezin een hangen naar het einde, terwijl juist dan, wanneer de uitgezondene wat gaat wennen aan klimaat en omgeving en het Bestuur volle waar voor zijn geld zal krijgen, dikwijls de bange vraag, welke toekomst hem in Holland wachten zal, reeds haar schaduw vooruitwerpt en vruchtbaar werken verhindert. Ingeval van ernstige ziekte is de gelegenheid om in een koelere luchtstreek wat bij te komen praktisch zoo goed als uitgesloten. 
Nog is met de terugkeer in Holland de lijdensweg niet ten einde, wanneer hem alsdan dikwijls blijkt, dat de toezeggingen van het Departement, bij het solliciteeren zoo gul gedaan, door verloop van tijd en wegens veranderde omstandigheden sterk in waarde verminderd zijn en dat hem, in plaats van waardeering voor zijn pioniersmoed, zonder welken een koloniale mogendheid niet bestaan kan, overal, ook in ambtelijke kringen, wantrouwen wacht, omdat hij het aangedurfd heeft een werkkring te zoeken in een gebiedsdeel, waarvan men de ligging op de kaart, nu ja, eigenlijk niet al te best weet. Het strijden moe, laat de eenmaal zoo stoutmoedige avonturier zich benoemen in een betrekking, waarvoor hij vroeger de neus zou hebben opgehaald.

Er is in West-Indië weer een verloren Hollandsche reputatie meer te boeken en als straks in de vacature opnieuw wordt voorzien, begint met den opvolger een nieuwe opvoering van het spel der Westindische teleurstellingen. Al heb ik zelf in vele opzichten vriendelijker herinneringen aan een zesjarig verblijf in Curaçao en Suriname, waar, naast veel bezwaren, toch ook zooveel goeds is, wat ik hier schets is een ervaring van leed, die ik als te algemeen leerde kennen, om niet de vraag te stellen, of voor de reputatie van Holland in West-Indië en van West-Indië in Holland, de tijd niet gekomen is om dit stuk nu eindelijk eens van het Koloniale repertoire af te voeren.

De tegenstelling tusschen het Oostindisch en Westindisch bestuurscorps als van een goed toegerust beroepscorps en één van toegewijde, intelligente dilettanten, vindt grootendeels haren grond in een verschil van structuur in beide gebiedsdeelen. Is in Oost-Indië de Hollander in de eerste plaats heerscher over onderworpen rassen, met eigen taal, recht en zeden, in West-Indië, waar volksplantingen zich hebben ontwikkeld uit elementen van ons eigen land, met oorspronkelijk geringe afwijkingen in taal en opvattingen, heeft zijn bestuurstaak zich aanvankelijk kunnen beperken tot het geven van leiding bij de toepassing van aan die van het Moederland meestal gelijkvormige wetten, eene zachte voogdij, waarvan het 
denkbaar is, dat de kolonist, de Surinamer, de Curaçaoenaar, zich op den duur zou kunnen ontrekken, ware het niet, dat in den loop der tijden daar gegroeide en verscherpte klassen- en rassentegenstellingen, welke het ééne volksdeel bij het andere verdacht doet zijn, een bestuur uit ,kinderen van het land” alleen, in werkelijkheid onmogelijk maakt. Op dit punt is niet veel veranderd. Indien thans echter een hervorming van het Westindische bestuurscorps overwogen zal moeten worden in de richting van grootere geschooldheid en betere voorbereiding voor zijn taak, zal dit vooral dienen te geschieden op grond van de gewijzigde, in belang sterk stijgende positie, welke voor West-Indië in de toekomst besloten ligt.

Curaçao is alreeds tot een wereldhaven gegroeid, Aruba is eveneens in de belangstelling voor petroleumbewerking getrokken, Suriname's positie en structuur is sterk aan het veranderen door de vestiging van vreemd kapitaal en de opkomst van den aan taal en zeden vasthoudenden Britsch-Indiër, terwijl, indien de bovengenoemde plannen van den Ondernemersraad slagen, naast het vreemde, het Oostindische kapitaal, en naast den Britsch-Indiër de Javaan een belangrijke plaats gaat innemen, waardoor het, misschien een groote, in ieder geval een belangwekkende toekomst tegemoet gaat, waarin voor West-Indië evenmin als voor Oost-Indië bestuursdilettantisme nog langer op zijn plaats zal zijn.

Hervorming kan in tweeërlei richting geschieden.

Ter zijde gelaten voor het oogenblik de hieronder nader te bespreken vraag, waarin de meer speciale technische bedrevenheid van den .Westindischen ambtenaar moet bestaan, zal in de eerste plaats moeten worden beslist, of met behoud van het bestaande stelsel deze vorming zal worden medegegeven aan van Holland uit te detacheeren dilettant-ambtenaren, dan wel of voor West-Indië eveneens zal worden dienstbaar gemaakt een georganiseerd, geschoold bestuurscorps, waarvoor dan op het oogenblik, praktisch gesproken, alleen maar het Oostindisch ambtenaarscorps in aanmerking komt, een stelsel noch nieuw van gedachte, noch onbekend in de toepassing. Laatstelijk 
werd het met een enkel woord door den Heer de Cock Buning bepleit ${ }^{1}$ ), terwijl nadat in de behoefte aan kader in de Westindische krijgsmacht vanuit Oost-Indië werd voorzien, daaronder de Militair-Geneeskundige Dienst begrepen, welke het leidend en zeer gewaardeerde personeel levert voor het Militair Hospitaal te Paramaribo, een gelukkig geslaagde praktijk hier den weg gedeeltelijk al gewezen heeft. Doch het krachtigste argument tot uitbouw van deze praktijk, ligt in beschikking welk Suriname daardoor krijgt over behoorlijk geschoolde en voor het bestuur over Javanen opgeleide krachten voor het werk dat noodig wordt om de immigratie van Javanen op groote schaal, naar de plannen van den Ondernemersraad tot een goed einde te brengen. Daartegenover is, dunkt mij, geen enkel deugdelijk argument voor het behoud van het bestaande stelsel aan te voeren.

Veel duurder behoeft bij wat overleg in het heen- en weer zenden der ambtenaren, de uitbreiding van de bestuursbemoeiing van het Oostindische corps niet te zijn. Het argument, dat de ervaring met Oostindische krachten voor West-Indië gebezigd, niet altijd gelukkig is uitgevallen, acht ik evenmin sterk, als dat voor behoud van het bestaande stelsel op grond dat nu en vroeger zoowel Hollanders als inheemsche krachten in rechterlijke macht en bestuur dikwijls uitnemende diensten bewijzen. Wat ik bepleit en ook de Heer de Cock Buning waarschijnlijk bedoelt, is niet de aanwending van individueele, uit OostIndië afkomstige krachten, als bijv. gepensionneerden, doch het systematisch dienstbaar maken van het geheele Oostindische bestuurscorps en zijn actief dienende leden aan West-Indië.

Wat West-Indië behoeft, is de beschikking over beroepsambtenaren, die geleerd hebben in een corps te dienen, die, wetend, dat hun verblijf daar slechts tijdelijk is, en dat bevordering naar vaste regels geschiedt, onver-

1) W. de Cock Buning, Rapport over Suriname, blz. 26: „men make meer gebruik van de opgeleide en ervaren krachten uit het Oost-Indische ambtenaarscorps." 
schilliger en rustiger staan tegenover intrigues, ambtenaren, die zonder zorgen voor de toekomst kalm hun plicht volbrengen. Hierin in de eerste plaats moet de hervorming haar kracht vinden.

Tot welke catagorieën van ambtenaren behoort zij zich uit te strekken? Er bestaat geen reden de Gouverneurs uit te zonderen.

Indien, zooals ik mij voorstel, dat in de toekomst geschieden zal, een ervaren Resident of Assistent-Resident steeds op zijn tijd en naar vaste regelen tot Gouverneur van Suriname of Curaçao wordt benoemd, zal dit aan de rust en de continuiteit in het bestuur ten goede komen.

Voorts komt bijna de geheele rechterlijke magistratuur voor recruteering uit het Oostindische corps in aanmerking, behalve wellicht dat in het Hof van Justitie van Curaçao één of twee plaatsen benevens het ambt van Procureur-Generaal aan ingezetenen kan worden voorbehouden en het ambt van President van het Hof in Suriname aan een meer blijvend element. In Suriname bestaat overigens één der grootste voordeelen van het nieuwe stelsel in de waarneming van het ambt van Districtscommissaris en dat van Agent-Generaal voor de Immigratie door ambtenaren van het Oostindische B.B., een werkkring geheel liggende in de lijn hunner ervaring. Voorts komen voor detacheering uit het Oostindische corps als regel in aanmerking: de Gouvernementssecretarissen, de hoofden van verschillende Departementen van Bestuur, als die betreffende den Geneeskundigen Dienst, Openbare Werken, Finantiën, Onderwijs; daarnevens de hoogere belastingambtenaren; voor Suriname in het bijzonder de Beheerder der Koloniale Vaartuigen, voor Curaçao de Gezaghebber der Bovenwindsche Eilanden. De detacheering zou nog in aantrekkelijkheid winnen, indien deze geschiedde met mogelijkheid van verplaatsing tusschen Suriname en Curaçao ${ }^{\mathbf{1}}$ ).

1) Zelfs onder het huidige stelsel zou hiermede reeds begonnen kunnen worden. De tijd van uitzending zou op die wijze verlengd kunnen worden waardoor de ,,bedrijfskosten" op den ambtenaar minder zouden komen te drukken. Het ambt zou aantrekkelijker worden, de bruikbaarheid van den ambtenaar verhoogd. 
Thans rest alleen de bespreking van de vraag, in hoeverre de detacheering in West-Indië voor de Oostindische ambtenaren bijzondere voorbereiding eischt.

Voor Curaçao mag men aannemen, dat de Hollandsche ambtenaar zich bij de uitoefening van zijn ambt op de Bovenwindsche Eilanden, hetzij als Gezaghebber, hetzij als Lid van het Hof van Justitie, in den aanvang althans zich wel redden kan met zijn door zelfstudie wat opgefrischt schoolengelsch. Voor de Benedenwindsche Eilanden echter, is bekendheid met het Papiamento, dat, naar ik reeds opmerkte, niet als het Negerengelsch in Suriname alleen door de volksklasse, doch tot in de hoogste kringen en op de bureaux als omgangstaal gebezigd wordt, wenschelijk.

Thans is bij de behandeling van de meeste creolen-zaken voor den Hollandschen rechter, een tolk onontbeerlijk. Het maakt hem klein en afhankelijk van zijn lager personeel. Hij leert het volk niet kennen, het volk hem niet. Ook de hoogere administratieve ambtenaren zullen wijs doen niet naar Curaçao uit te gaan zonder van het Negerspaansch eenigermate op de hoogte te zijn. Aan het Departement van Koloniën zal het niet moeilijk vallen te 's-Gravenhage een geschikte kracht te vinden om hun die kennis bij wijze van voorbereiding bij te brengen.

Voor Suriname is kennis van het Negerengelsch, dat onder het volk gesproken wordt en bovendien in het verkeer tusschen den creool en de Britsch Indiërs en Javanen de rol speelt van een soort esperanto, zoowel voor den rechter als voor de meeste administratieve ambtenaren zeer gewenscht. Het maakt hem meer dan tot dusverre, onafhankelijk van zijn omgeving, leert hem door eigen ooren te hooren.

Van meer belang is echter bekendheid met den BritschIndiër en den Javaan, hun taal, zeden en opvattingen. Ook op dit punt is het moeilijk geen satyre te schrijven over het dilettantisme in Suriname's bestuur. De BritschIndiër is thans bijna meer dan een halve eeuw in de Kolonie, hij maakt van de geheele bevolking ongeveer een vierde gedeelte uit. Niettemin staan Bestuur en bevol- 
king tegenover zijn taal en zeden volkomen vreemd. Dit is uit een politiek oogpunt vooral gevaarlijk. De nationale stroomingen uit het land van zijn afkomst, werken, zoo zegt men, ook in op den Surinaamschen afstammeling. Doch hoe en in welke richting? Is de Britsch-Indiër met ons bestuur, met onze rechtspraak tevreden? Hoe reageert hij op de Nederlandsche wet? Wij weten het eigenlijk niet. De Britsch-Indiër staat sterk op zijn recht: hij is daardoor voor den bestuursambtenaar zoowel als voor den rechter in Suriname de hoofdfiguur. Contact is echter slechts mogelijk met behulp van tolken. Zijn wij er zeker van, dat ook bij de ook in Suriname tusschen Hindoe's en Mahomedanen bestaande vijandige gezindheid, dit element den tolken bij het verleenen hunner tusschenkomst onbewust geen parten spelen kan? Meer dan elders is hier tolkenrechtspraak voor den conscientieusen rechter onbevredigend ${ }^{\mathbf{1}}$ ).

Wat den Javaan betreft, ook zijn taal en zeden zijn voor Bestuur zoowel als voor de bevolking een gesloten boek. Als bestuursobject is hij gemakkelijk, te gemakkelijk vaak, bij de tolken bestaat minder reden eenzijdigheid te vermoeden. Doch als contractant is hij een waardevol bezit; onrechtvaardige beslissingen te zijnen opzichte kunnen economisch zoowel als politiek de meest ernstige gevolgen na zich sleepen.

Zelfs de plantageopzichters weten zich als regel slechts gebrekkig voor den Javaanschen arbeider verstaanbaar te maken. Hoeveel gevallen van „desertie”, van „onwil om te werken" voor den rechter aangebracht, zijn wellicht het gevolg van slecht verstaan en half begrijpen?

1) Om door een daad te getuigen van mijn ernstige meening, dat er in Suriname gebroken moet worden met het stelsel van onverschilligheid en onkunde aangaande den Britsch-Indiër, heb ik den uitnemenden kenner van diens taal en zeden, den Hernhutter-Missionaris Rev. R. Karsten daar aangezocht en bereid gevonden eene eenvoudige, ook voor zelfstudie geschikte Hollandsch-Hindi grammatica samen te stellen, benevens een, wat ik zou willen noemen „Handboek over den Surinaamschen Britsch-Indiër.” Ofschoon aan de uitgave van dergelijke geschriftjes, waarvoor uitteraard slechts een beperkt debiet te verwachten is, finantieele bezwaren verbonden zijn, bestaat er uitżicht met steun van belangstellenden daarin op den duur toch te slagen. 
Naar ,adat" wordt in Suriname niet gevraagd, het Nederlandsche recht is voor ieder hetzelfde, aan verschillende behandeling van verschillende bevolkingsgroepen heeft de wetgever van 1868 niet gedacht, kòn dat ook niet doen. Kan dit zoo blijven, wanneer Suriname een overwegend Javanenland wordt? Aan zulke zeer gewichtige punten zullen op Javanen ingestelde Oostindische ambtenaren uitteraard meer aandacht geven, en op die wijze voor een deel nog aan den Javaan in Suriname kunnen goed maken, wat door onkunde bedorven is. Voor hun volledige technische voorbereiding voor het werk in Suriname zal dan alleen nog noodig zijn kennis van den Britsch-Indiër, zijn taal en zeden. Als leervak voor hunne opleiding zal deze kennis op den duur bij het onderwijs niet mogen ontbreken. Bij wijze van overgang zal voor den thans dienenden Oostindischen ambtenaar een verblijf van enkele maanden, bij het passeeren in Nederland wellicht voldoende zijn om zich die kennis althans bij benadering eigen te maken. Ik heb reden aan te nemen, dat o.a. aan de Leidsche Universiteit bij de betreffende faculteit belangstelling zal worden gevonden voor een praktischen cursus in Britsch-Indische talen. Daarmede zou, in samenwerking met het Departement van Koloniën reeds een stap in de goede richting worden gedaan. Ik dring hierop met kracht aan, desnoods reeds voor de op den bestaanden voet uit te zenden ambtenaren. De Regeering kan bovendien door het geven van een toelage zooals in Oost-Indië voor minder gekende Indonesische talen geschiedt, die studie aanmoedigen.

Dit alles echter betreft de uitvoering der voorgestelde hervorming. Deze zal geen bezwaar ontmoeten, indien maar eenmaal het beginsel is aanvaard, dat ook bij den opbouw van West-Indië, in bestuur en rechtspraak het beste nog niet goed genoeg is.

Heemstede, Februari 1927 